\title{
LIXIVIAÇÃO DO INSETICIDA THIAMETHOXAM EM MACROLISÍMETROS DE DUAS CLASSES DE SOLO ${ }^{1}$
}

\author{
Leaching of the insecticide thiamethoxam in macrolysimeters of two soil classes
}

\author{
Nélio Ricardo Amaral Castro², Renê Luís de Oliveira Rigitano ${ }^{3}$, José Maria de Lima ${ }^{4}$, Mário César Guerreiro ${ }^{5}$
}

\begin{abstract}
RESUMO
Investigou-se a lixiviação do inseticida thiamethoxam em dois solos da região de Lavras-MG, pertencentes às classes Latossolo Vermelho Acriférrico típico $\left(\mathrm{LV}_{\mathrm{wf}}\right)$ e Argissolo Vermelho-Amarelo Distrófico típico (PVA $)$. Foram utilizados macrolisímetros desses solos, com 1,0 m de diấmetro e 0,45, 0,90 e 1,80 m de profundidade, os quais foram obtidos mantendo-se a estrutura original dos solos. A aplicação do inseticida foi feita no início do período chuvoso, utilizando-se o produto comercial Actara $250 \mathrm{WG}$, o qual foi diluído em $100 \mathrm{~mL}$ de água e aplicado na superfície dos lisímetros. Os lisímetros foram mantidos sem vegetação e sob regime hídrico natural. A água percolada nos mesmos, até o final do segundo período chuvoso após a aplicação, foi coletada e analisada com relação à concentração de thiamethoxam, cuja determinação foi feita por CLAE. Os resultados mostraram alta mobilidade do thiamethoxam em ambos os solos, sendo que sua lixiviação foi mais intensa no $\mathrm{PVA}_{\mathrm{d}}$ do que no $\mathrm{LV}_{\mathrm{wf}}$. As porcentagens totais de thiamethoxam lixiviadas abaixo de $0,45 \mathrm{~m}$ foram, em média, equivalentes a 53,8 e $19,4 \%$ da quantidade aplicada, respectivamente para o $\mathrm{PVA}_{\mathrm{d}} \mathrm{e} \mathrm{LV}_{\mathrm{wf}}$. Resíduos de thiamethoxam foram detectados também na água percolada nos lisímetros de 0,90 e 1,80 m de ambos os solos. Embora o estudo tenha sido conduzido em solos sem vegetação, os resultados obtidos indicaram elevado potencial de lixiviação do thiamethoxam nos solos estudados, em condições práticas de uso desse inseticida.
\end{abstract}

Termos para indexação: Pesticida, lisímetro, contaminação, água do subsolo.

\section{ABSTRACT}

The leaching of thiamethoxam in two Brazilian soils, a typic Acriferric Red Latosol $\left(\mathrm{LV}_{\mathrm{wf}}\right)$ and a typic Dystrophic RedYellow Argisol (PVA), was investigated in macrolysimeters $(1.0 \mathrm{~m}$ diameter and depth of $0.45,0.90$ and $1.80 \mathrm{~m})$ of undisturbed material of the soils, which were kept without vegetation and under field conditions. The insecticide was applied at the beginning of the rainy season, using the formulation Actara $250 \mathrm{~W} 囚$, which was diluted in $100 \mathrm{~mL}$ of water and applied on the lysimeters surface. The water percolated through the lysimeters was collected until the end of rainy season of the following year, with samples being taken for determination of thiamethoxam concentration, performed by HPLC. The results showed a high mobility of thiamethoxam in both soils, with more intense leaching of the compound in the PVA than in the $\mathrm{LV}_{\mathrm{wf}}$. The total amounts of thiamethoxam leached below $0.45 \mathrm{~m}$ were equivalent to 53.8 and $19.4 \%$ of the applied amount, respectively for the PVA ${ }_{d}$ and $L_{\text {wf }}$. Thiamethoxam residues were also found in the water collected from the 0.90 and $1.80 \mathrm{~m}$ lysimeters of both soils. These results indicate a high potential of thiamethoxam leaching under practical conditions of its use in the studied soils, despite the lack of vegetation.

Index terms: Pesticide, lysimeter, contamination, groundwater.

\section{(Recebido em 4 de novembro de 2005 e aprovado em 18 de setembro de 2007)}

\section{INTRODUÇÃO}

Os pesticidas são insumos agrícolas importantes na atividade agrícola atual, para a obtenção de níveis competitivos de produtividade. Contudo, muitos desses produtos são tóxicos a organismos não-alvo e, portanto, a contaminação de recursos hídricos com resíduos desses compostos pode afetar esses organismos, incluindo os seres humanos. A contaminação do lençol freático, segundo alguns pesquisadores (SAEED et al., 1996; TORNISIELO et al., 1998), constitui-se numa preocupante forma de poluição ambiental causada por pesticidas.

\footnotetext{
${ }^{1}$ Trabalho financiado pelo CNPq. Parte da tese apresentada à Universidade Federal de Lavras (UFLA) pelo primeiro autor, como um dos requisitos do curso de doutorado em Entomologia Agrícola

¿Engenheiro Agrônomo, Doutor em Entomologia - Divisão de Análise de Risco de Pragas/DARP - Departamento de Sanidade Vegetal/DSV - Ministério da Agricultura, Pecuária e Abastecimento/MAPA - Esplanada dos Ministérios, Bloco D, Anexo B - Setor Cívico-Administrativo - 70043-900 - Brasília, DF-nelio.castro@agricultura.gov.br

${ }^{3}$ Engenheiro Agrônomo, PhD em Entomologia, Professor Titular - Departamento de Entomologia/DEN - Universidade Federal de Lavras/UFLA Cx. P 3037 - 37200-000 - Lavras, MG - rigitano@ufla.br - Bolsista do CNPq

${ }^{4}$ Engenheiro Agrônomo, Doutor em Ciência do Solo, Professor Adjunto - Departamento de Ciência do Solo/DCS - Universidade Federal de Lavras/UFLA Cx. P 3037 - 37200-000 - Lavras, MG - jmlima@ufla.br - Bolsista do CNPq

${ }^{5}$ Engenheiro Químico, Doutor em Química, Professor Adjunto - Departamento de Química/DQI - Universidade Federal de Lavras/UFLA - Cx. P 3037 37200-000 - Lavras, MG - guerrero@ufla.br
}

Ciênc. agrotec., Lavras, v. 32, n. 6, p. 1818-1823, nov./dez., 2008 
Quanto menor a adsorção de um pesticida nos colóides do solo, maior a sua susceptibilidade à lixiviação, ou seja, seu arraste pela água que percola o solo. A maioria dos pesticidas atualmente utilizados são compostos nãoiônicos ou não-ionizáveis. Vários estudos (BRIGGS, 1981; CANELLAS et al., 1999; CHIOU, 1990) mostraram que a adsorção de pesticidas não-ionizáveis em solos ocorre principalmente na matéria orgânica, e que quanto mais polar a molécula, menor o seu coeficiente de adsorção em solos e maior o seu potencial de lixiviação.

Outros estudos têm mostrado que a incidência de chuvas intensas logo após a aplicação de pesticidas pode resultar em rápido transporte desses compostos através dos macroporos presentes na zona não-saturada dos solos, em condições de não-equilíbrio de adsorção (LARSSON \& JARVIS, 1999; SCORZA JÚNIOR et al., 2004; ZEHE \& FLÜHLER, 2001). Esse rápido transporte de pesticidas no solo, conhecido como transporte preferencial, aumenta os riscos de contaminação do lençol freático com resíduos desses compostos, devido ao fato de a camada superficial do solo, reconhecidamente com maior capacidade de adsorção e degradação, ser ultrapassada mais rapidamente. Sob condições de campo, Jarvis et al. (1995) comentam que o transporte preferencial de pesticidas em solos deve ser considerado regra e não exceção.

O inseticida thiamethoxam apresenta propriedades e características similares a pesticidas detectados na água do lençol freático em várias partes dos Estados Unidos, ou sejam, polaridade relativamente alta $\left(\log \mathrm{K}_{\mathrm{ow}}=-0,2\right)$, baixo coeficiente de sorção $\left(\mathrm{K}_{\mathrm{oc}}=32\right.$ a 70) e estabilidade moderada a alta em solos $\left(\mathrm{t}_{1 / 2}=47\right.$ a 385 dias) (ANTUNESKENYON \& KENNEDY, 2001). Em um estudo conduzido em colunas de $30 \mathrm{~cm}$ de quatro solos diferentes, com aplicação do thiamethoxam na superfície das colunas e subseqüente aplicação de água em quantidade equivalente a $200 \mathrm{~mm}$ de precipitação pluvial, Robinson (2001) relatou que as quantidades totais do composto lixiviadas nas colunas chegaram a $23 \%$ da quantidade aplicada, com valores maiores para os solos mais arenosos.

O thiamethoxam foi recentemente introduzido no Brasil para o controle de insetos-praga de diversas culturas. Na cafeicultura, o composto é aplicado ao solo, visando o controle do bicho-mineiro das folhas do cafeeiro, Leucoptera coffeella (Guérin-Mèneville, 1842) (Lepidoptera: Lyonetiidae). O uso do thiamethoxam em lavouras cafeeiras no Brasil tem se intensificado nos últimos anos, embora pouco se saiba sobre o seu destino em nossos solos.
Face ao exposto, objetivou-se com este trabalho investigar a lixiviação do thiamethoxam em macrolisímetros de duas classes de solos representativos do Brasil, em condições de campo, a fim de avaliar o potencial de contaminação do lençol freático e, conseqüentemente, de poços e nascentes com resíduos desse inseticida, em condições práticas de seu uso.

\section{MATERIAL E MÉTODOS}

A lixiviação do thiamethoxam foi investigada em macrolisímetros de solos das classes Latossolo Vermelho Acriférrico típico $\left(\mathrm{LV}_{\mathrm{wf}}\right)$ e Argissolo Vermelho-Amarelo Distrófico típico $\left(\mathrm{PVA}_{\mathrm{d}}\right.$ ), no período de novembro de 2002 a abril de 2004, sob regime hídrico natural.

As colunas de solo foram implantadas em 1983, utilizando a metodologia descrita por Souza (1983). Tais colunas de solo foram coletadas em cilindros de aço de 1,0 $\mathrm{m}$ de diâmetro com $0,45 \mathrm{~m}, 0,90 \mathrm{~m}$ e 1,80 m de profundidade, mantendo-se a estrutura original dos solos. A base de cada lisímetro foi conectada a uma tubulação de aço para coleta da água percolada.

A aplicação do thiamethoxam foi realizada no dia 23 de novembro de 2002, utilizando-se o produto Actara 250 WG® $\left(250 \mathrm{~g}\right.$ de tiamethoxam $\left.\mathrm{kg}^{-1}\right)$. Assumindo-se a área do lisímetro equivalente a uma cova de cafeeiro, foram aplicados $100 \mathrm{~mL}$ de uma solução aquosa de thiamethoxam contendo $140 \mathrm{mg}$ do ingrediente ativo em cada lisímetro. Por causa das restrições impostas pelo número de lisímetros disponíveis, foram utilizadas duas repetições para cada profundidade do lisímetro, para os dois solos. A remoção da vegetação na superfície dos lisímetros foi efetuada durante todo o período experimental. Os dados climatológicos foram obtidos junto à Estação Meteorológica da UFLA, a cerca de $40 \mathrm{~m}$ da área experimental.

A água percolada nos lisímetros foi coletada em recipientes de aço inox, com capacidade de 15 L. Após a medição do volume de água em cada coleta, uma subamostra de $5 \mathrm{~mL}$ da mesma foi filtrada em membrana PTFE $(0,45 \mu \mathrm{m})$ e armazenada em freezer até ser analisada. Para a determinação quantitativa dos resíduos de thiamethoxam foi utilizado um cromatógrafo líquido, modelo Agilent 1100 Series, operando com detector de ultravioleta $(255 \mathrm{~nm})$. Utilizou-se uma coluna LiChroCART (25 $\mathrm{cm}$ de comprimento e $3 \mathrm{~mm}$ de diâmetro interno) preenchida com LiChrospher RP-18, $5 \mu \mathrm{m}$. A fase móvel utilizada foi uma solução de $\mathrm{H}_{2} \mathrm{O}$ Milli-Q: acetonitrila, na proporção $65: 35$, com um fluxo de $0,3 \mathrm{~mL} \mathrm{~min}^{-1}$. Nestas 
condições, o tempo de retenção do thiamethoxam foi em torno de 6 minutos e 40 segundos. A concentração de thiamethoxam nas amostras foi calculada com base nas curvas de calibração, as quais foram obtidas injetando-se soluções padrões do composto nas concentrações de 0,4 e 2,0 ng $\mu \mathrm{L}^{-1}$, mantidos os volumes de injeção em $20 \mu \mathrm{L}$. O padrão analítico utilizado foi obtido junto à Syngenta Proteção de Cultivos Ltda., tendo especificação de pureza acima de $99 \%$.

\section{RESULTADOS E DISCUSSÃO}

Os dados de precipitação pluvial e temperatura do ar durante o período experimental, expressos como médias semanais, são apresentados na Figura 1.

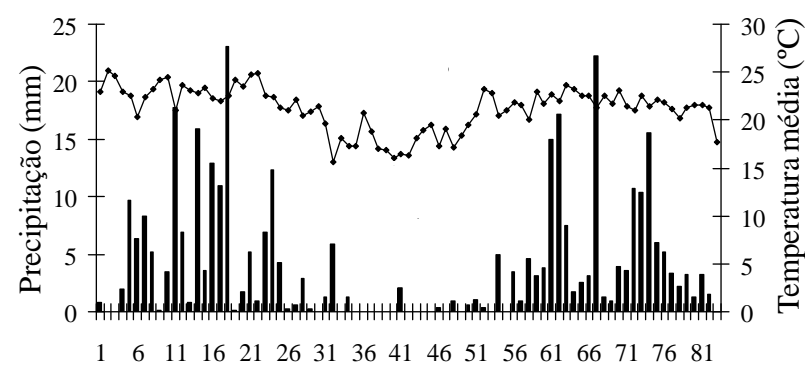

Figura 1 - Dados de precipitação pluvial (mm) e temperatura média do ar $\left({ }^{\circ} \mathrm{C}\right)$, expressos como médias semanais, no período de 01/10/2002 a 30/04/2004.

As concentrações de thiamethoxam na água percolada nos lisímetros de $0,45 \mathrm{~m}$ dos dois solos, durante todo o período experimental, são mostradas na Figura 2.

Foram detectados resíduos de thiamethoxam já nas primeiras amostras de água coletada nos lisímetros do PVA, sendo que as concentrações máximas do inseticida (próximas de $0,5 \mathrm{mg} \mathrm{L}^{-1}$ ) foram verificadas por volta de dois meses após aplicação. No final do primeiro período chuvoso, as concentrações do composto na água percolada nos lisímetros desse solo foram relativamente baixas, indicando pequena quantidade do mesmo ainda remanescente nesses lisímetros. Com relação aos lisímetros do $\mathrm{LV}_{\mathrm{wf}}$, a detecção inicial do thiamethoxam e as concentrações máximas do composto na água percolada ocorreram um pouco mais tarde em comparação com o PVA . As concentrações máximas do inseticida foram menores no caso do $\mathrm{LV}_{\text {wf }}$ e o subseqüente decréscimo nas concentrações foi mais gradual nesse solo, revelando que a lixiviação do thiamethoxam foi mais rápida no PVA ${ }_{\mathrm{d}}$.

Os resultados obtidos nos lisímetros de $0,90 \mathrm{~m}$ (Figura 3) também mostraram uma lixiviação mais intensa do thiamethoxam no PVA do que no $\mathrm{LV}_{\mathrm{wf}}$.

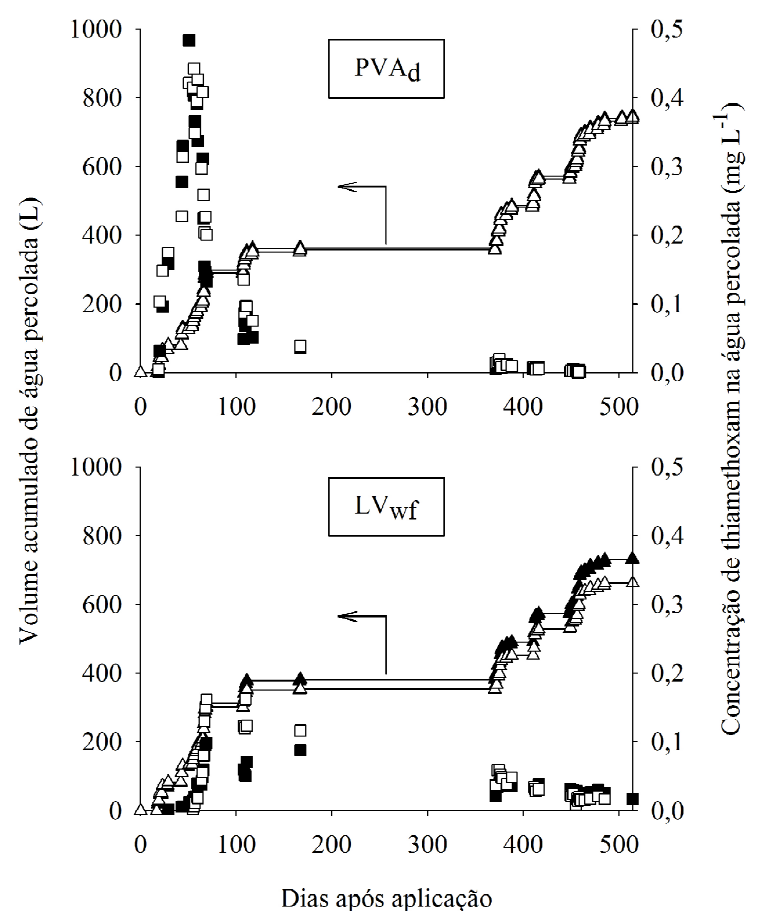

Figura 2 - Volume acumulado de água percolada e concentração de resíduos de thiamethoxam nos lisímetros de 0,45 m do Argissolo Vermelho-Amarelo Distrófico típico $\left(\mathrm{PVA}_{\mathrm{d}}\right)$ e do Latossolo Vermelho Acriférrico típico $\left(\mathrm{LV}_{\mathrm{wf}}\right)$. Pontos cheios e vazios referem-se às duas repetições.

Em ambos os solos, as concentrações do composto na água percolada no início do segundo período chuvoso foram comparáveis àquelas observadas no final do primeiro período chuvoso, indicando alta estabilidade do thiamethoxam nos solos estudados.

Resíduos de thiamethoxam foram encontrados também na água percolada nos lisímetros de 1,80 m (Figura 4). Como esperado, em conseqüência da maior profundidade desses lisímetros, os tempos de detecção inicial do composto na água percolada nos dois solos foram maiores do que aqueles verificados nos lisímetros de menores profundidades, sendo que no caso do $\mathrm{LV}_{\mathrm{wf}}$ foram detectados resíduos somente na água percolada no segundo período chuvoso, confirmando a lixiviação menos intensa do thiamethoxam nesse solo.

As quantidades totais do thiamethoxam lixiviadas nos lisímetros, calculadas com base na quantidade aplicada do produto, são apresentadas na Tabela 1. A quantidade lixiviada do composto abaixo de $0,45 \mathrm{~m}$ no solo $\mathrm{PVA}_{\mathrm{d}}$ ultrapassou a metade da dose aplicada do mesmo. Os lisímetros de 1,80 $\mathrm{m}$ do $\mathrm{PVA}_{\mathrm{d}}$ foram os que apresentaram a maior discrepância entre as repetições, quanto às 


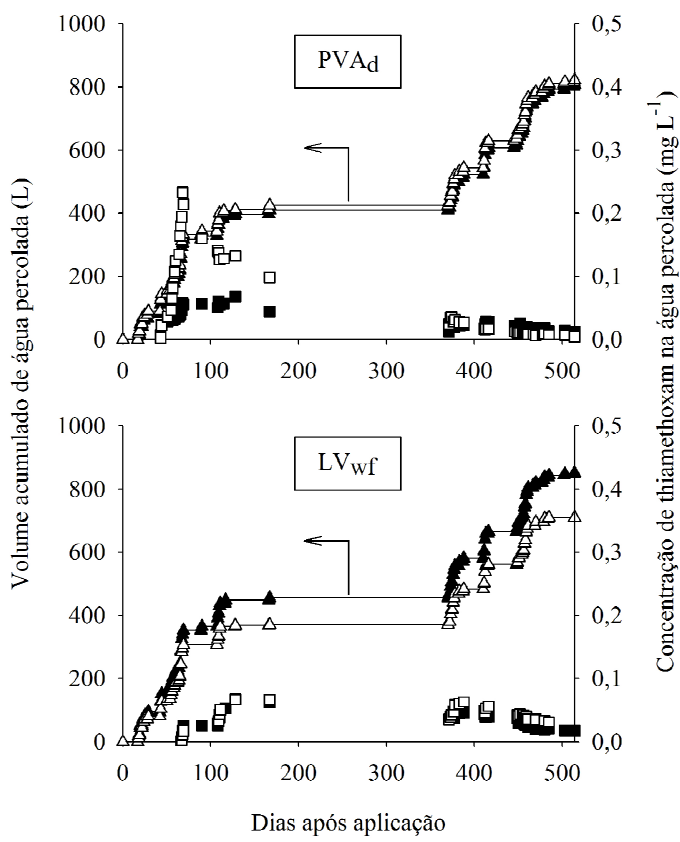

Figura 3 - Volume acumulado de água percolada e concentração de resíduos de thiamethoxam nos lisímetros de 0,90 m do Argissolo Vermelho-Amarelo Distrófico típico $\left(\mathrm{PVA}_{\mathrm{d}}\right)$ e do Latossolo Vermelho Acriférrico típico $\left(\mathrm{LV}_{\mathrm{wf}}\right)$. Pontos cheios e vazios referem-se às duas repetições.

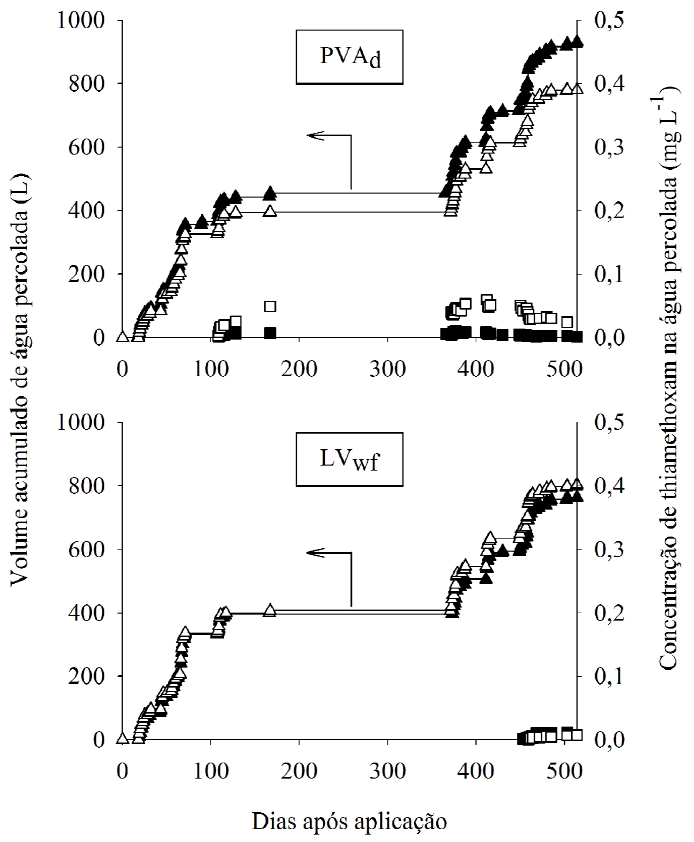

Figura 4 - Volume acumulado de água percolada e concentração de resíduos de thiamethoxam nos lisímetros de 1,80 m do Argissolo Vermelho-Amarelo Distrófico típico $\left(\mathrm{PVA}_{\mathrm{d}}\right)$ e do Latossolo Vermelho Acriférrico típico $\left(\mathrm{LV}_{\mathrm{wf}}\right)$. Pontos cheios e vazios referem-se às duas repetições.

Tabela 1 - Quantidade de resíduos lixiviada (\%) em relação ao total aplicado nos lisímetros de diferentes profundidades, nas classes de solo Argissolo Vermelho-Amarelo Distrófico típico $\left(\mathrm{PVA}_{\mathrm{d}}\right)$ e Latossolo Vermelho Acriférrico típico $\left(\mathrm{LV}_{\mathrm{wf}}\right)$.

\begin{tabular}{ccccccccc}
\hline \multirow{2}{*}{$\begin{array}{c}\text { Profundidade } \\
(\mathrm{m})\end{array}$} & \multicolumn{9}{c}{$\mathrm{LV}_{\mathrm{wf}}$} \\
\cline { 2 - 9 } & Lisímetro & $1^{\circ}$ ano & $2^{\circ}$ ano & Total & Lisímetro & $1^{\circ}$ ano & $2^{\circ}$ ano & Total \\
\cline { 2 - 9 } 0,45 & I & 10,13 & 7,66 & 17,79 & I & 49,61 & 1,36 & 50,97 \\
& II & 13,98 & 6,94 & 20,92 & II & 55,03 & 1,69 & 56,72 \\
\hline \multirow{2}{*}{0,90} & I & 3,22 & 9,71 & 12,93 & I & 9,38 & 5,81 & 15,19 \\
& II & 2,14 & 10,61 & 12,75 & II & 28,54 & 4,85 & 33,39 \\
\hline \multirow{2}{*}{1,80} & I & 0,00 & 0,58 & 0,58 & I & 0,19 & 1,72 & 1,91 \\
& II & 0,00 & 0,17 & 0,17 & II & 0,70 & 11,85 & 12,55 \\
\hline
\end{tabular}

quantidades totais lixiviadas $(1,91$ e $12,55 \%$ da dose aplicada), sendo esta atribuída à variabilidade espacial existente nesse solo, indicando a necessidade de um número maior de repetições, o que não foi possível pelo número limitado de lisímetros.

A lixiviação mais intensa do thiamethoxam no $\mathrm{PVA}_{\mathrm{d}}$ em relação ao $\mathrm{LV}_{\mathrm{wf}}$ é atribuída, ao menos em parte, à menor sorção e menor taxa de degradação do composto no PVA ${ }_{\mathrm{d}}$.
Castro (2005) investigou a sorção e degradação do thiamethoxam em amostras dos horizontes A e B destes solos, obtendo valores de $\mathrm{K}_{\mathrm{f}}$ (coeficiente de sorção de Freundlich) do inseticida, respectivamente para os horizontes A e B, de 1,1 e 0,68 para o $\mathrm{LV}_{\text {wf }}$ e de 0,54 e 0,11 para o PVA d Com relação à degradação, os valores de meia-vida obtidos por Castro (2005), respectivamente para os horizontes A e B, foram 173 e 301 dias para o $\mathrm{LV}_{w f}$ e 256 
e 315 dias para o PVA. Embora os valores de meia-vida no horizonte B tenham sido semelhantes, o efeito da degradação sobre a lixiviação do thiamethoxam pode ter sido importante nas primeiras semanas após a aplicação, quando o composto encontrava-se predominantemente na camada mais superficial dos solos.

A lixiviação mais intensa do thiamethoxam no PVA pode ter sido decorrente também da diferença na estrutura dos solos. Enquanto o $\mathrm{LV}_{\text {wf }}$ possui estrutura granular, o PVA $_{d}$ apresenta estrutura em blocos, o que favorece maior incidência de macroporos. O fluxo preferencial da água por esses macroporos pode ter resultado em transporte mais rápido do composto no $\mathrm{PVA}_{\mathrm{d}}$. Tal transporte preferencial de pesticidas em solos já foi constatado por outros autores (LARSSON \& JARVIS, 1999; SCORZA JÚNIOR et al., 2004;ZEHE \& FLÜHLER, 2001).

Os resultados obtidos neste trabalho mostraram expressiva lixiviação do thiamethoxam nos solos estudados, quando mantidos sem vegetação e com a aplicação do produto no início do período chuvoso. A lixiviação do composto em solos cultivados é esperada ser menor devido à evapotranspiração da água e à transferência do inseticida para as raízes e parte aérea das plantas. Franco \& Inforzato (1950) mostraram que um cafezal adulto, no espaçamento $3,5 \times 3,5 \mathrm{~m}$, transpira ao longo do ano o equivalente a cerca de $40 \%$ da água da precipitação pluvial. No entanto, conforme verificado por esses autores, a precipitação é muito superior à transpiração no período chuvoso do ano. Assim, os resultados obtidos no presente trabalho indicam que a incidência de chuvas pesadas após a aplicação do thiamethoxam, em condições práticas de uso desse inseticida, pode comprometer a sua eficiência.

Admitindo-se um padrão de lixiviação do thiamethoxam, em condições práticas de uso do mesmo, igual ao observado neste trabalho, os riscos de contaminação do lençol freático com níveis tóxicos para os seres humanos dependem da profundidade do lençol freático e da toxicidade desse inseticida. A ingestão diária aceitável (IDA) do thiamethoxam para o homem é de 0,02 mg Kg-1 de peso corpóreo dia ${ }^{-1}$ (ROBINSON, 2001). Considerando a concentração máxima de thiamethoxam encontrada na água percolada nos lisímetros de $0,90 \mathrm{~m}$ do PVA $_{d}\left(0,29 \mathrm{mg} \mathrm{L}^{-1}\right)$, uma criança de $10 \mathrm{Kg}$ que bebesse $1 \mathrm{~L}$ dessa água por dia, estaria ingerindo uma quantidade do composto equivalente a $0,029 \mathrm{mg} \mathrm{Kg}^{-1} \mathrm{dia}^{-1}$, ou seja, maior do que a IDA. Ressalte-se que, para os países da União Européia, a concentração máxima admissível para qualquer pesticida em água potável foi estabelecida em $0,0001 \mathrm{mg} \mathrm{L}^{-1}$ (BARCELÓ, 1993). Neste trabalho, as concentrações máximas de thiamethoxam na água percolada nos lisímetros foram muito maiores do que esse valor, mesmo no caso dos lisímetros de $1,80 \mathrm{~m}$ de profundidade.

Os solos estudados neste trabalho são tipicamente profundos, com o lençol freático comumente localizado a vários metros de profundidade. Contudo, considerando que a taxa de degradação do thiamethoxam é esperada ser menor com o aumento da profundidade do solo, e que até duas aplicações do inseticida por ano são recomendadas, os resultados indicam que o thiamethoxam não deve ser aplicado em áreas com poços ou nascentes nas proximidades, principalmente no caso de Argissolos em relevo mais acidentado, que são menos profundos.

\section{CONCLUSÕES}

$\mathrm{O}$ inseticida thiamethoxam revelou-se altamente lixiviável em macrolisímetros de material indeformado dos solos Latossolo Vermelho Acriférrico típico $\left(\mathrm{LV}_{\mathrm{wf}}\right)$ e Argissolo Vermelho-Amarelo Distrófico típico $\left(\mathrm{PVA}_{\mathrm{d}}\right)$, mantidos sem vegetação e sob chuva natural.

A lixiviação do thiamethoxam no $\mathrm{PVA}_{d}$ foi mais intensa do que no $\mathrm{LV}_{\mathrm{wf}}$, o que é atribuído, ao menos em parte, à menor sorção e maior estabilidade do composto no primeiro.

A aplicação prática do thiamethoxam nesses solos, no início do período chuvoso, visando o controle do bichomineiro das folhas do cafeeiro, pode resultar no transporte de quantidades apreciáveis do composto abaixo de 0,50 m e, portanto, reduzir a sua disponibilidade para absorção pelo sistema radicular do cafeeiro.

Em condições práticas de uso do thiamethoxam nos solos estudados, os riscos de contaminação do lençol freático com resíduos do composto são apreciáveis, especialmente em áreas onde esses solos sejam pouco profundos.

\section{REFERÊNCIAS BIBLIOGRÁFICAS}

ANTUNES-KENYON, S. E.; KENNEDY, G. Thiamethoxam: a new active ingredient review. Massachusetts: Pesticide Bureau, 2001. Disponível em: $<$ http://WwW.state.ma.us/dfa/ 'pesticides/water/REVIEW THIAMETHOXAM.pdf خ. Acesso em: 18 mar. 2002.

BARCELÓ, D. Environmental Protection Agency and other methods for the determination of priority pesticides and their transformation products in water. Journal of Chromatography A, New York, v. 643, n. 1/2, p. 117-143, 1993. 
BRIGGS, G. G. Theoretical and experimental relationship between soil adsorption, octanol-water partition coefficients, water solubilities, bioconcentration factors, and the parachor. Journal of Agriculture and Food Chemistry, Washington, v. 29, p. 1050-1059, 1981.

CANELLAS, L. P.; SANTOS, G. A.; AMARAL SOBRINHO, N. M. B. Reações da matéria orgânica. In: SANTOS, G. A.; CAMARGO, F. A. O. Fundamentos da matéria orgânica do solo. Porto Alegre: Gênesis, 1999. p. 69-90.

CASTRO, N. R. A. Sorção, degradação e lixiviação do inseticida thiamethoxam em Latossolo e Argissolo. 2005. 161 p. Tese (Doutorado em Entomologia Agrícola) Universidade Federal de Lavras, Lavras, 2005.

CHIOU, C. T. Roles of organic matter, minerals, and moisture in sorption nonionic compounds and pesticides by soil. In: MAcCARTHY, P. et al. (Eds.). Humic substances in soil and crop sciences: selected readings. Madison: ASA/ SSSA, 1990. p. 111-149.

FRANCO, C. M.; INFORZATO, R. Quantidade de água transpirada pelo cafeeiro cultivado ao sol. Bragantia, Campinas, v. 10, n. 9, p. 247-257, 1950.

JARVIS, N. J.; BERGSTRÖM, L. F.; BROWN, C. D. Pesticide leaching models and their use for management purposes. In: ROBERTS, T. R.; KEARNEY, P. C. (Eds.). Environmental behaviour of agrochemicals. New York: J. Willey, 1995. p. 185-220.

LARSSON, M. H.; JARVIS, N. J. Evaluation of a dualporosity model to predict field-scale solute transport in a macroporous soil. Journal of Hydrology, Amsterdam, v. 215, p. 153-171, 1999.

ROBINSON, P. Evaluation of the new active thiamethoxam in the product Cruiser 350 FS insecticide seed treatment. Victoria: National Registration Authority for Agricultural and Veterinary_Chemicals, 2001. Disponível em: <http:// www.apvma.gov.au/publications/prsthi.pdf. Acesso em: 2 jun. 2003.

SAEED, I. A. M.; HARKIN, J. M.; ROUSE, D. I. Leaching of methyl isothiocyanate in plainfield sand chemigated with metan-sodium. Pesticide Science, Oxford, v. 46, p. 375380, 1996.

SCORZA JÚNIOR, R. P.; SMELT, J. H.; BOESTEN, J. J. T. I.; HENDRIKS, R. F. A.; ZEE, S. E. A. T. M. van der. Preferential flow of bromide, bentazon, and imidacloprid in a dutch clay soil. Journal of Environmental Quality, Madison, v. 33, p. 1473-1486, 2004.

SOUZA, J. J. de. Complemento de uma bateria de lisímetros: coleta dos solos e implantação do complexo. In: ESCOLA SUPERIOR DE AGRICULTURA DE LAVRAS. Materiais corretivos: relatório final. Lavras, 1983. p. 171-198.

TORNISIELO, V. L.; PINHO, R. S.; FURLAN, G. R.; COSTA, M. A. Lixiviação do inseticida ${ }^{14} \mathrm{C}$-endosulfan em solos do estado de São Paulo. Pesticidas: Revista de Ecotoxicologia e Meio Ambiente, Curitiba, v. 8, p. 1-8, 1998.

ZEHE, E.; FLÜHLER, H. Preferential transport of isoproturon at a plot scale and a field scale tile-drained site. Journal of Hydrology, Amsterdam, v. 247, p. 100-115, 2001. 